\title{
A cutaneous mixed tumor in a dog
}

\author{
Ken-ichi WATANABE ${ }^{1,2)}$, James K. CHAMBERS ${ }^{2)}$, Kazuyuki UCHIDA2)*, \\ Kazumi NIBE ${ }^{3)}$, Nanako USHIO ${ }^{2)}$, Noriyuki HORIUCHI ${ }^{1)}$, Yoshiyasu KOBAYASHI ${ }^{1}$ \\ and Hiroyuki NAKAYAMA ${ }^{2)}$
}

\author{
1)Department of Veterinary Medicine, Research Center for Global Agromedicine, Obihiro University of \\ Agriculture and Veterinary Medicine, Obihiro 080-0834, Japan \\ ${ }^{2)}$ Department of Veterinary Pathology, Graduate School of Agricultural and Life Sciences, The University of \\ Tokyo, Tokyo 113-8657, Japan \\ 3) Japan Animal Referral Medical Center Kawasaki, Kanagawa 213-0032, Japan
}

J. Vet. Med. Sci.

79(3): 670-673, 2017

doi: $10.1292 /$ jvms.16-0610

Received: 25 November 2016 Accepted: 17 January 2017 Published online in J-STAGE: 28 January 2017
ABSTRACT. The atypical cutaneous tumor of a 9-year-old mixed breed female dog was examined. The tumor was well-demarcated and histologically composed of a trichoblastic area, tricholemmal area and apocrine glandular area. Neoplastic cells in trichoblastic area and tricholemmal area had PAS-positive granules in the cytoplasm and were positive for pan-cytokeratin, cytokeratin $5 / 6,14$ and 19 and p63. Neoplastic cells in trichoblastic area were also positive for cytokeratin 15 and CD34. Neoplastic cells in apocrine glandular area were positive for pan-cytokeratin and cytokeratin 7, 18 and 19. Myoepithelial cell proliferation with osteocartilaginous metaplasia was observed in this area. Since neoplastic cells showed multiphenotypic differentiation for hair follicles and apocrine glands, the present case was diagnosed as a cutaneous mixed tumor.

KEY WORDS: cutaneous mixed tumor, dog, hair follicle, multiphenotypic differentiation

Adnexal tumors are common in dogs. In the World Health Organization (WHO) classification of tumors of domestic animals, adnexal tumors have been categorized into five fascicles [1]: follicular tumors, nailbed tumors, sebaceous and modified sebaceous gland tumors, apocrine and modified apocrine gland tumors, and eccrine gland tumors, based on their differentiation patterns. However, adnexal tumors rarely show multiphenotypic differentiation; the complexity of their histological appearance results in diagnostic difficulties $[7,8]$.

In human pathology, a cutaneous mixed tumor is an uncommon benign adnexal tumor formerly called "chondroid syringoma" [6]. The tumor is well-circumscribed and composed of a mixture of epithelial and stromal components with a wide spectrum of differential patterns. The epithelial component consists of solid, follicle and tubular structures mainly with apocrine and eccrine differentiation. The follicular differentiation of epithelial components also occurs in some cases [2, 3]. The stromal component shows chondroid, myxoid and fibrous differentiation. Local recurrence is uncommon, and the prognosis of the tumor is very good.

In the present study, we describe the morphological findings and immunohistochemical profiles of a canine case of an atypical adnexal tumor with follicular and apocrine differentiation similar to a human cutaneous mixed tumor.

A nine-year-old mixed breed female dog was brought to a local veterinary clinic for a cutaneous mass on the head. The mass was round, well-circumscribed and approximately $10 \mathrm{~mm}$ in diameter. One year later, the mass increased to approximately $20 \mathrm{~mm}$ in diameter with ulceration on the surface. Excision was performed, and the mass was submitted to the Japan Animal Referral Medical Center for a histological examination. An immunohistochemical examination was performed at the University of Tokyo.

The mass was fixed in 10\% neutral-buffered formalin and embedded in paraffin. Paraffin sections were stained with hematoxylin and eosin (HE) and periodic acid-Schiff (PAS). Immunohistochemistry (IHC) was performed using the primary antibodies listed in Table 1. Some sections were pretreated for antigen retrieval as shown in Table 1. Sections were treated with 3\% hydrogen peroxide $\left(\mathrm{H}_{2} \mathrm{O}_{2}\right)$-methanol at room temperature for $5 \mathrm{~min}$ and incubated in $10 \%$ skimmed milk Tris-buffered saline with $0.1 \%$ Tween 20 (TBST) at $37^{\circ} \mathrm{C}$ for 40 min to avoid non-specific reactions. Sections were incubated at $4^{\circ} \mathrm{C}$ overnight with primary antibodies. After being washed three times in TBST, the sections were incubated with Envision horseradish peroxidase (HRP) mouse or rabbit polymers (Dako-Japan, Kyoto, Japan) at $37^{\circ} \mathrm{C}$ for $30 \mathrm{~min}$. Sections were washed again and visualized with $0.05 \%$ 3-3'diaminobenzidine (DAB) and $0.01 \% \mathrm{H}_{2} \mathrm{O}_{2}$ in $0.05 \mathrm{M} \mathrm{pH7.6}$ Tris- $\mathrm{HCl}$ buffer. Counterstaining was performed with Mayer's hematoxylin.

The mass was located from the dermis to subcutaneous tissue and was well-demarcated. It was indistinctly separated into three areas based on morphological patterns (Fig. 1). In trichoblastic area, the peripheral area of the tumor, small basaloid epithelial

*Correspondence to: Uchida, K., Department of Veterinary Pathology, Graduate School of Agricultural and Life Sciences, The University of Tokyo, Yayoi 1-1-1, Bunkyo-ku, Tokyo 113-8657, Japan. e-mail: auchidak@mail.ecc.u-tokyo.ac.jp

(02017 The Japanese Society of Veterinary Science

This is an open-access article distributed under the terms of the Creative Commons Attribution Non-Commercial No Derivatives (by-nc-nd) License. (CC-BY-NC-ND 4.0: https://creativecommons.org/licenses/by-nc-nd/4.o/) 
Table 1. Primary antibodies and protocols for immunohistochemistry

\begin{tabular}{lcccc}
\hline \multicolumn{1}{c}{ Antibody } & Clone & Dilution & Source & Antigen retrieval \\
\hline Pan-Cytokeratin & AE1/AE3 & $1: 200$ & Dako & - \\
Cytokeratin 5/6 & D5/16 B4 & $1: 50$ & Dako & pH9.0 Autoclave \\
Cytokeratin 7 & OV-TL 12/30 & $1: 100$ & Dako & Proteinase K \\
Cytokeratin 14 & NCL-LL002 & $1: 50$ & Leica & pH6.0 Autoclave \\
Cytokeratin 15 & LHK15 & $1: 50$ & Thermo & - \\
Cytokeratin 18 & Ks18.04 & ready to use & PROGEN & Proteinase K \\
Cytokeratin 19 & b170 & ready to use & Leica & Proteinase K \\
CD34 & (polyclonal) & $1: 80$ & Santa Cruz & pH6.0 Autoclave \\
p63 & BC4A4 & $1: 100$ & Biocare Medical & pH6.0 Autoclave \\
$\alpha$-SMA & 1A4 & $1: 100$ & Dako & - \\
\hline
\end{tabular}

Table 2. Results of immunohistochemistry on neoplastic cells and normal cutaneous adnexal tissue

\begin{tabular}{|c|c|c|c|c|c|c|c|c|c|c|}
\hline & Pan-CK & CK 5/6 & CK14 & CK7 & CK18 & CK15 & CK19 & CD34 & p63 & $\alpha$-SMA \\
\hline \multicolumn{11}{|l|}{ Normal tissue } \\
\hline Dermal papilla & - & - & - & - & - & - & - & - & - & - \\
\hline Hair matrix & - & - & - & - & - & - & - & - & + & - \\
\hline Hair shaft medulla & + & + & - & - & - & - & - & - & - & - \\
\hline Hair shaft cortex & + & - & - & - & - & - & - & - & - & - \\
\hline Inner root sheath & - & - & - & - & - & - & - & - & - & - \\
\hline Outer root sheath isthmus & ++ & ++ & ++ & - & + & + & + & + & ++ & - \\
\hline Outer root sheath infundibulum & ++ & + & ++ & - & - & $++^{\text {a) }}$ & - & + & + & - \\
\hline Sebaceous gland & + & + & + & - & - & \pm & - & - & \pm & + \\
\hline Apocrine gland glandular epithelium & + & - & - & + & + & + & + & - & - & - \\
\hline Apocrine gland myoepithelium & + & + & + & - & + & - & - & - & + & + \\
\hline \multicolumn{11}{|l|}{ Neoplastic cells } \\
\hline Small round cell, trichoblastic area & ++ & ++ & + & - & - & + & + & + & ++ & - \\
\hline Clear polygonal cell, tricholemmal area & + & + & + & - & - & - & \pm & + & + & - \\
\hline Glandular epithelial cell, apocrine glandular area & ++ & - & - & + & + & + & + & - & - & - \\
\hline Glandular myoepithelial cell, apocrine glandular area & ++ & + & + & - & + & - & - & - & + & + \\
\hline
\end{tabular}

CK, cytokeratin; -, negative; +, positive; ++, strongly positive. a); outermost layer only.

cells formed narrow branching cords with mucinous or fibrous stroma (medusoid pattern) (Fig. 2). Neoplastic cells had a clear cytoplasm and small round nuclei with a few mitotic figures. The cytoplasm was strongly positive for PAS. In tricholemmal area, the central area of the tumor, clear polygonal cells resembling an external root sheath formed island patterns surrounded by a thick fibrous capsule (Fig. 3). Neoplastic cells had a clear to pale cytoplasm with some PAS-positive glycogen granules and oval nuclei with a few pleomorphic and mitotic figures. The same granules were also present in normal external root sheaths. Neoplastic cells showed follicular keratinization within the follicle. In apocrine glandular area, the deep area of the tumor, polygonal cells formed a biphasic multitubular pattern with myoepithelial cell proliferation (Fig. 4). Neoplastic cells had an eosinophilic cytoplasm and oval nuclei. Myoepithelial cells showed osteocartilaginous metaplasia.

The results of IHC are summarized in Table 2. In the normal follicle, the outer root sheath was strongly positive for pancytokeratin (AE1/AE3), cytokeratin 5/6 and 14, and p63. In the deep area, the outer root sheath isthmus was positive for cytokeratin 18 and 19 and CD34. The outermost layer of the outer root sheath infundibulum at the insertion point of the arrector pili muscle is called the bulge area. This area was positive for cytokeratin 15 . The apocrine gland glandular epithelium was positive for pan-cytokeratin and cytokeratin 7, 15, 18 and 19. Apocrine gland myoepithelial cells were positive for pan-cytokeratin, cytokeratin 5/6, 14 and 18, p63 and $\alpha$-smooth muscle actin ( $\alpha$-SMA) (Figs. 5, S1). In trichoblastic area of the mass, neoplastic cells were positive for cytokeratin 14; and strongly positive for pan-cytokeratin, cytokeratin 5/6 and p63. Positive ratios of neoplastic cells for stem cell markers (cytokeratin 15, 19 and CD34) were as follows; cytokeratin 15: 28.5\%, cytokeratin 19: 58.5\% and CD34: 39.5\% (Figs. 6, S2). In tricholemmal area, neoplastic cells were positive for pan-cytokeratin, cytokeratin 5/6 and 14 and p63. Positive ratios of neoplastic cells for the stem cell markers were as follows; cytokeratin 15: $0 \%$, cytokeratin 19: $3.5 \%$ and CD34: $32.5 \%$ (Figs. 7, S3). The IHC characteristics of these two cell types were similar to those of the external root sheath. In apocrine glandular area, neoplastic glandular epithelial cells were positive for pan-cytokeratin and cytokeratin 7, 18 and 19 (Figs. 8, S4). Positive ratios of glandular epithelial cells for the stem cell markers were as follows; cytokeratin 15: 100\%, cytokeratin 19: 100\% and CD34: $0 \%$. Neoplastic myoepithelial cells were positive for pan-cytokeratin, cytokeratin 5/6, 14 and 18, p63 and $\alpha$-SMA; and negative for the stem cell markers. These immunohistochemical characteristics of neoplastic cells were similar to those of the apocrine gland. 

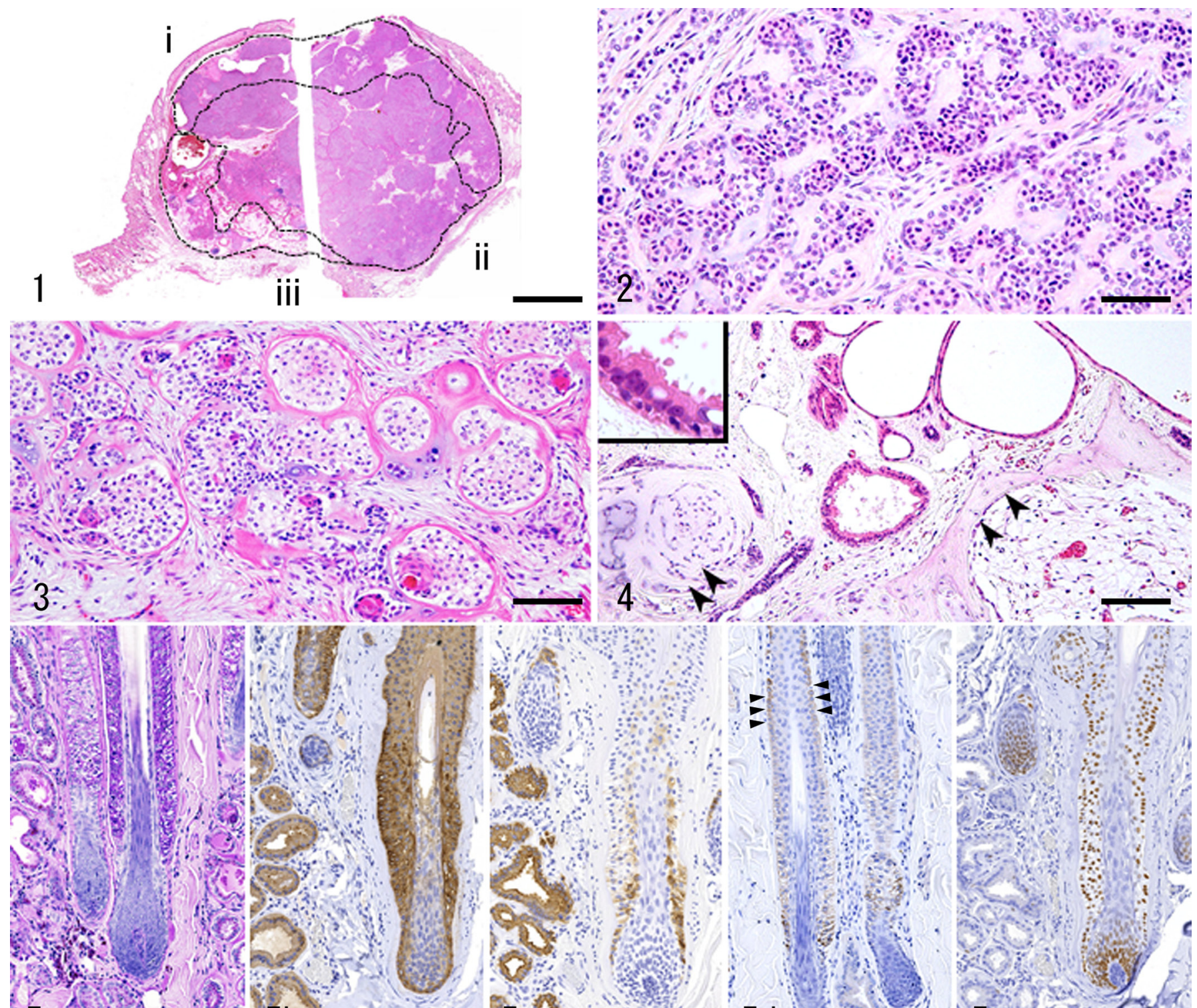

$5 a-5 n-5 b-502$
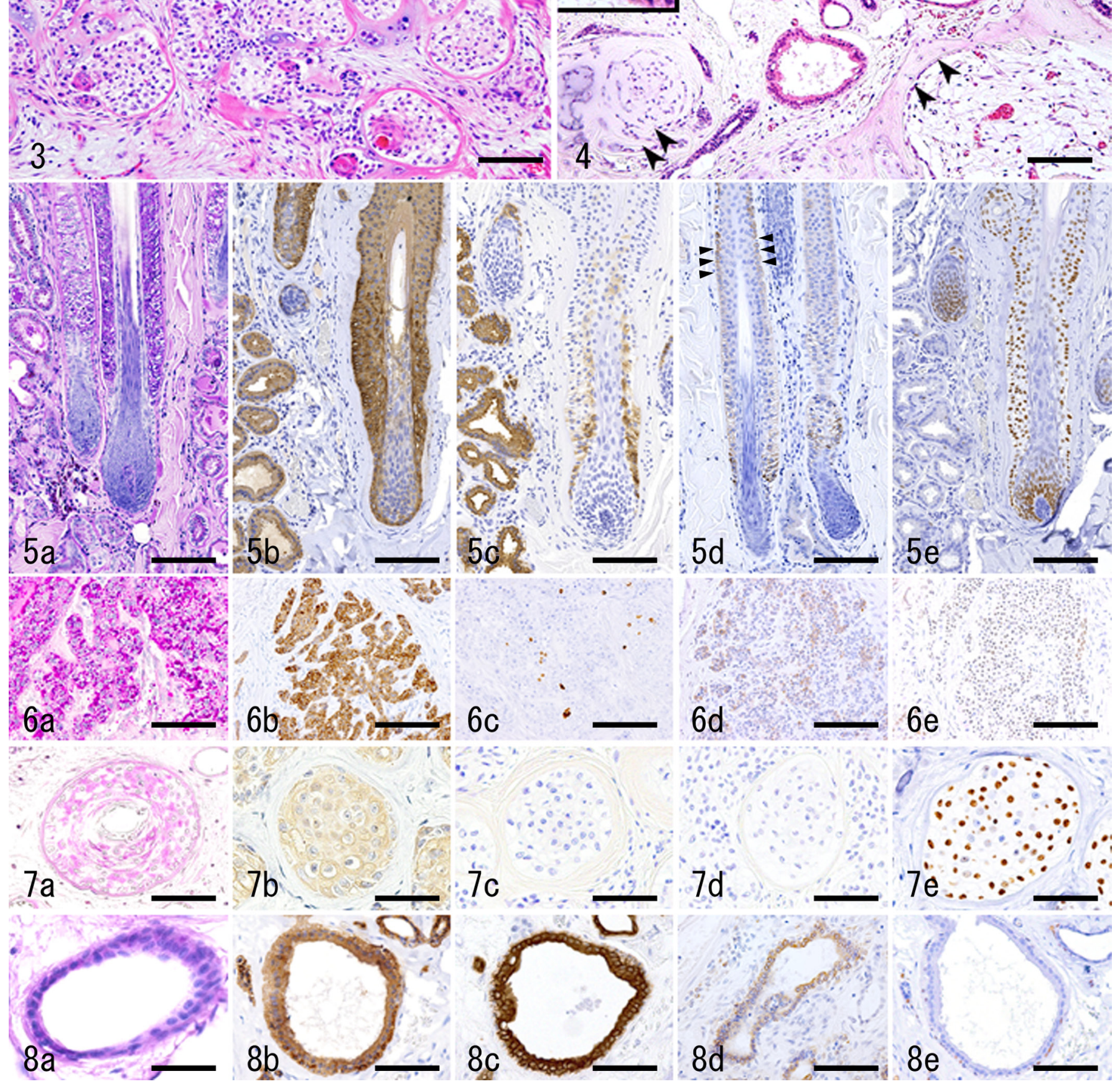

$7 d$
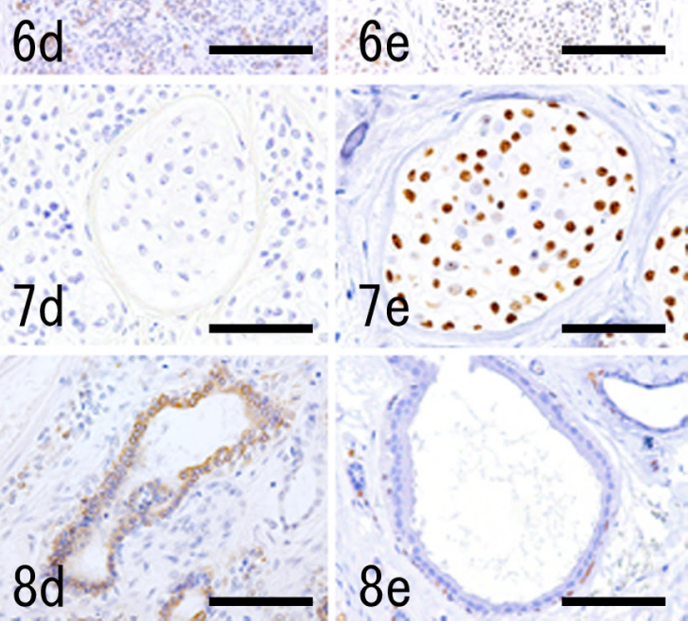
Histological and IHC examinations revealed follicular differentiation (trichoblastic area and tricholemmal area) and apocrine differentiation in tumor tissue. Regarding the follicular component, trichoblastic primitive hair germ and external root sheath differentiation were predominant. These areas were continuous, and the borders between the different components were unclear; therefore, the tumor was more likely to be a follicular tumor with multiphenotypic differentiation than a collision tumor. In addition, osteocartilaginous metaplasia was observed within apocrine glandular area of tumor. Based on these results, the tumor was diagnosed as the cutaneous mixed tumor of the dog. In the WHO classification of tumors of domestic animals, there is no category for adnexal tumors with multiphenotypic differentiation [1]. In humans, these tumors are categorized as "cutaneous mixed tumors", with tumors with the osteocartilaginous differentiation of myoepithelial cells being categorized as chondroid syringoma [6]. Adnexal tumors with multiphenotypic differentiation are rare in humans and animals, and there have been no reports of a cutaneous mixed tumor in a dog. Sharif et al. reported two canine cases of an adnexal tumor with an external root sheath and sebaceous gland differentiation as clear cell type trichoblastoma [8]. Clear cell type trichoblastoma is a recent variant with the proliferation of small epithelial cells with a vacuolated cytoplasm, and only a few cases have been reported in humans [9, 10]. In these reports, the origins of tumor cells were not elucidated; some cases showed external root sheath differentiation [10], whereas others displayed sebaceous gland differentiation [9]. Sebaceous gland differentiation was not observed in the present case; however, follicular differentiation and apocrine gland differentiation with osteocartilaginous metaplasia were detected. Kobayashi et al. previously demonstrated that canine hair stem cells in the bulge area have multipotency for follicular and adnexal differentiation similar to human hair stem cells and are positive for the hair stem cell markers, cytokeratin 15 and 19 [4, 5]. In the present case, trichoblastic cells in area 1 were positive for cytokeratin 15 and 19 and CD34, indicating the hair stem cell features of tumor cells. The present study describes a case of an atypical cutaneous tumor with multiphenotypic differentiation in a dog. The IHC results of the tumor and normal canine skin tissue provided will contribute to the identification of adnexal differentiation in a canine cutaneous mixed tumor.

\section{REFERENCES}

1. Goldschmidt, M. H., Dunstan, R. W., Stannard, A. A., von Tscharner, C., Walder, E. J. and Yager, J. A. 1998. Tumors of the Skin of Domestic Animals., 2nd ser., vol. 3 (Schulman, F. Y. ed.), Armed Forces Institute of Pathology, Washington, D.C.

2. Hassab-el-Naby, H. M., Tam, S., White, W. L. and Ackerman, A. B. 1989. Mixed tumors of the skin. A histological and immunohistochemical study. Am. J. Dermatopathol. 11: 413-428. [Medline] [CrossRef]

3. Headington, J. T. 1961. Mixed tumors of skin: eccrine and apocrine types. Arch. Dermatol. 84: 989-996. [Medline] [CrossRef]

4. Janes, S. M., Lowell, S. and Hutter, C. 2002. Epidermal stem cells. J. Pathol. 197: 479-491. [Medline] [CrossRef]

5. Kobayashi, T., Iwasaki, T., Amagai, M. and Ohyama, M. 2010. Canine follicle stem cell candidates reside in the bulge and share characteristic features with human bulge cells. J. Invest. Dermatol. 130: 1988-1995. [Medline] [CrossRef]

6. LeBoit, E., Burg, G., Weedon, D. and Sarashin, A. 2006. Pathology and Genetics of Skin Tumors. World Health Organization Classification of Tumors, International Agency for Research on Cancer (IARC), Lyon.

7. Mineshige, T., Yasuno, K., Sugahara, G., Tomishita, Y., Shimokawa, N., Kamiie, J., Nishifuji, K. and Shirota, K. 2014. Trichoblastoma with abundant plump stromal cells in a dog. J. Vet. Med. Sci. 76: 735-739. [Medline] [CrossRef]

8. Sharif, M. and Reinacher, M. 2006. Clear cell trichoblastomas in two dogs. J. Vet. Med. A Physiol. Pathol. Clin. Med. 53: 352-354. [Medline] [CrossRef]

9. Tronnier, M. 2001. Clear cell trichoblastoma in association with a nevus sebaceus. Am. J. Dermatopathol. 23: 143-145. [Medline] [CrossRef]

10. Wang, L., Wang, G., Yang, L. and Gao, T. 2009. Multiple clear cell trichoblastoma. J. Cutan. Pathol. 36: 370-373. [Medline] [CrossRef]

Fig. 1. Low magnification of the cutaneous mass. The mass is well-demarcated and separated into three areas: i) a trichoblastic area, ii) tricholemmal area and iii) apocrine glandular area. Hematoxylin and eosin (HE) stain. Bar=5 mm.

Fig. 2. Trichoblastic area of the mass. HE stain. Bar=100 $\mu \mathrm{m}$.

Fig. 3. Tricholemmal area of the mass. HE stain. Bar=100 $\mu \mathrm{m}$.

Fig. 4. Apocrine glandular area of the mass. HE stain. Bar=100 $\mu \mathrm{m}$. Insert: High magnification of neoplastic cells. Neoplastic cells showed apocrine secretion. Arrowhead: Osteocartilaginous metaplasia of myoepithelial cells.

Fig. 5. PAS stain and immunohistochemistry of a normal hair follicle. Bar=200 $\mu \mathrm{m}$. a: PAS stain. b: Pan-Cytokeratin (AE1/AE3). c: Cytokeratin 18. d: Cytokeratin 15. e: p63. Arrowhead: bulge area.

Fig. 6. PAS stain and immunohistochemistry of the trichoblastic area. Bar=200 $\mu \mathrm{m}$. a: PAS stain. b: Pan-Cytokeratin (AE1/AE3). c: Cytokeratin 18. d: Cytokeratin 15. e: p63.

Fig. 7. PAS stain and immunohistochemistry of the tricholemmal area. Bar=50 $\mu \mathrm{m}$. a: PAS stain. b: Pan-Cytokeratin (AE1/AE3). c: Cytokeratin 18. d: Cytokeratin 15. e: p63.

Fig. 8. PAS stain and immunohistochemistry of the apocrine glandular area. Bar=100 $\mu$ m. a: PAS stain. b: Pan-Cytokeratin (AE1/AE3). c: Cytokeratin 18. d: Cytokeratin 15. e: p63. 